\title{
Integrating the Water Framework Directive into the Habitats Directive: Analysis of distribution patterns of lacustrine EU habitats in lakes of Lombardy (northern Italy)
}

\author{
Rossano BOLPAGNI,${ }^{*}$ Mattia M. AZZELLA, ${ }^{2}$ Chiara AGOSTINELlI,${ }^{3}$ Andrea BEGHI, ${ }^{3}$ Eugenia BETTONI, ${ }^{3}$ \\ Guido BRUSA, ${ }^{4}$ Cristina DE MOLLI,${ }^{4}$ Riccardo FORMENTI,${ }^{3}$ Filippo GALIMBERTI, ${ }^{3}$ Bruno E.L. CERABOLINI ${ }^{4}$
}

${ }^{1}$ Department of Chemical Science, Life and Environmental Sustainability, University of Parma, Viale G.P. Usberti 33/A, 43124 Parma, Italy; ${ }^{2}$ Via G. Bellucci 94, 00156 Rome, Italy; ${ }^{3}$ Lombardy Regional Environmental Protection Agency, Via Rosellini 17, 20124 Milan, Italy; ${ }^{4}$ Department of Theoretical and Applied Sciences, University of Insubria, Via J.H. Dunant 3, 21100 Varese, Italy

*Corresponding author: rossano.bolpagni@unipr.it

\begin{abstract}
The existence of strong potential synergies between the Water Framework Directive (WFD) and the Habitats Directive (HD) is widely acknowledged. Indeed, ensuring favourable conservation conditions for aquatic habitats and species of conservation concern is closely related to the achievement of a good ecological status in water bodies. However, since these two sets of European laws are generally applied without any coordination, an inefficient use of resources may adversely affect their goals. The main negative outcome is an increase in the cost of monitoring programs for collecting data in nature (i.e., physical and chemical parameters, species and habitats, plant communities). The use of macrophytes as a bioindicator, as imposed by the WFD, may instead help to integrate data on aquatic EU habitats and enhance knowledge of such habitats outside the Natura 2000 network. The aim of present study was to evaluate the usefulness of data collected in WFD monitoring surveys as a means of inferring the occurrence and the distribution of lacustrine aquatic habitats in countries belonging to the European Union (EU). The main aim of the analysis was to identify the depth gradient distribution of diagnostic macrophyte taxa in two EU habitats (3140, i.e., Chara-dominated benthic communities, and 3150, i.e., natural eutrophic lakes) using data collected in lakes in Lombardy (northern Italy), some of which are included in the Natura 2000 network (10 out 16). While recognizing the limitations of the data collected within the two frameworks, the results confirmed the marked usefulness of WFD data as a means of enhancing the knowledge available on lacustrine aquatic habitats in the EU. WFD data can actively help to improve the basic information on aquatic habitats, thereby more effectively supporting regional strategies for biodiversity conservation as well as recovery programs.
\end{abstract}

Key word: WFD; HD; monitoring programs; aquatic vegetation; vascular macrophytes; charophytes; nutrient drivers; macrophyte depth distribution.

\section{INTRODUCTION}

The Water Framework Directive (WFD, European Union, 2000) and the Habitats Directive (HD, European Union, 1992) are strongly interrelated (Janauer et al., 2015). The synergy between these two directives represents an intriguing goal aimed at pursuing an effective conservation of aquatic ecosystems. It being universally accepted that the achievement of favourable conservation conditions for aquatic habitats or species of conservation concern is closely related to the possibility of guaranteeing a good ecological status of colonized water bodies (Janauer et al., 2015). However, each of these directives is currently implemented on its own, thereby potentially hampering the achievement of their respective goals (Beunen et al., 2009). One major effect of the lack of coordination between the directives is an increase in the cost of monitoring programs for collecting data in nature (i.e., physical and chemical parameters, species and habitats, plant communities). Indeed, the synergy and potential conflicts between these directives have mainly been investigated in terms of the attainment of their respective goals rather than of the possible reciprocal operational support (Ecke et al., 2010; Collins et al., 2012; Janauer et al., 2015).

WFD monitoring activities include both biotic elements and physical and chemical features (European Union, 2000), providing the opportunity to integrate the structural/compositional investigation of biotic communities with their environmental drivers (e.g., hydro-morphological, physical and chemical determinants). Indeed, the depth distribution of lacustrine macrophytes is affected by several ecological factors: light (Canfield et al., 1985; Chambers and Kalff, 1985), phosphorus (Søndergaard et al., 2013), temperature and depth of the thermocline (Genkai-Kato and Carpenter, 2005), and pressure (Dale, 1986). Although light seems to be the most representative ecological factor, phosphorus availability is also important on account of the role it plays in the regulation of macrophyte distribution in a lake as well as of their occurrence 
at the regional scale (Duarte and Kalff, 1990). Furthermore, the maximum depth of macrophyte colonization $\left(\mathrm{Zc}_{\max }\right)$ is strongly dependent on the size of the lake, which is in turn directly regulates the depth of the thermocline (Genkai-Kato and Carpenter, 2005). Where water transparency is high, the $\mathrm{Zc}_{\max }$ is greater in large lakes than in medium-sized and small lakes (Azzella et al., 2014a, 2014b). These factors may be useful for monitoring the conservation status of aquatic European Union (EU) habitats if we bear in mind that that the HD reporting activities are - inter alia - based on an evaluation of the area and range occupied by habitats (Evans and Arvela, 2011).

The level of information available for aquatic vegetation is generally far lower than that available for terrestrial vegetation. A greater integration between these two directives may represent a win-win strategy to fill the gaps in knowledge on aquatic vegetation and to assess the effectiveness of WFD legislation in improving the quality of water bodies. This is particularly interesting if we consider that aquatic ecosystems are among the ecosystems threatened most on a worldwide scale and that, besides the inherent difficulties associated with sampling, the cost of providing reliable data is high (e.g., boat availability, poor weather conditions, wind) (Azzella et al., 2013a).

A potential change in this scenario may lie in the WFD. It provides for the use of several biotic communities as a means of assessing the quality status of water bodies, including macrophytes, fish and macroinvertebrates, which are actually the same target elements as those found in the HD (Janauer et al., 2015). By focusing on lacustrine macrophytes, we may be able to integrate the HD database with routine monitoring information yielded by the WFD. Indeed, almost all the aquatic vegetation in lakes, whether it is dominated by vascular plants or charophytes, can be referred to the conservation habitats defined by the HD (European Union, 1992; Bolpagni, 2013a).

The main aim of the present study was to verify the occurrence of the EU habitat codes 3140 and 3150 by using WFD data, both within and outside the Natura 2000 network in Lombardy. By considering the depth distribution of their diagnostic taxa, we also investigated the predictive role of water transparency (expressed as SD) in modelling the depth distribution of lacustrine EU habitats.

\section{METHODS}

\section{Study area}

The study was conducted on data collected from 16 different lakes in the Lombardy Region (northern Italy), 10 of which are included in the Natura 2000 network (Tab. 1; Fig. 1). The lakes covered a wide range of ecological conditions (Tab. 2), both as regards their physical (e.g., depth) and trophic (e.g., water transparency investigated by means of Secchi disk, SD) characteristics. Lake depth ranged from $3 \mathrm{~m}$ (Lake Ganna) to $370 \mathrm{~m}$ (Lake Maggiore), whereas the SD ranged from $\sim 0.80-1.00 \mathrm{~m}$ (lakes of Mantova) to $8.42 \mathrm{~m}$ (Lake Monate).

\section{Macrophyte EU target habitats}

The target habitats of the present study are the EU habitats 3140 (hard oligo-mesotrophic waters with benthic vegetation of Chara spp.) and 3150 (natural eutrophic

Tab. 1. Interactions between lakes and Natura 2000 network; the official name of the site, its national code and type, as well as the percentage of the lacustrine area included in the site is reported for each lake included in a Natura 2000 site. The overall assessment of EU habitat 3150 is also included (updated in February 2016).

\begin{tabular}{|c|c|c|c|c|c|}
\hline Lake & Natura 2000 site name & National code & Type & LA & 3150 \\
\hline Comabbio & Lago di Comabbio & IT2010008 & $\mathrm{SAC}$ & $100 \%$ & B \\
\hline Ganna & Lago di Ganna & IT2010001 & SAC & $100 \%$ & \\
\hline Iseo & Torbiere d'Iseo & IT2070020 & SAC/SPA & $<1 \%$ & B \\
\hline \multirow[t]{2}{*}{ Maggiore } & Canneti del Lago Maggiore & IT2010502 & SPA & $<1 \%$ & B \\
\hline & Palude Bruschera & IT2010015 & SAC & $<1 \%$ & $\mathrm{~B}$ \\
\hline \multirow[t]{2}{*}{ Mantova Superior } & Ansa e Valli del Mincio & IT20B0017 & SAC & $40 \%$ & $\mathrm{C}$ \\
\hline & Valli del Mincio & IT20B0009 & SPA & $100 \%$ & $\mathrm{C}$ \\
\hline Mantova Middle & Valli del Mincio & IT20B0009 & SPA & $100 \%$ & $\mathrm{C}$ \\
\hline Mantova Inferior & Valli del Mincio & IT20B0009 & SPA & $100 \%$ & $\mathrm{C}$ \\
\hline \multirow[t]{2}{*}{ Mezzola } & Lago di Mezzola e Pian di Spagna & IT2040042 & SAC & $100 \%$ & A \\
\hline & Lago di Mezzola e Pian di Spagna & IT2040022 & SPA & $100 \%$ & A \\
\hline Montorfano & Lago di Montorfano & IT2020004 & SAC & $100 \%$ & \\
\hline \multirow[t]{2}{*}{ Varese } & Alnete del Lago di Varese & IT2010022 & SAC & $<1 \%$ & B \\
\hline & Lago di Varese & IT2010501 & SPA & $100 \%$ & $\mathrm{~B}$ \\
\hline
\end{tabular}

LA, lacustrine area; SAC, Special Area of Conservation; SPA, Special Protection Areas; A, excellent value; B, good value; C, significant value. 
lakes with Magnopotamion or Hydrocharition-type vegetation). The former includes oligo- to meso-trophic waters with well-developed benthic vegetation dominated by stoneworts (charophytes); the latter includes the freefloating and rhizophytic plant communities of eutrophic lakes (Biondi et al., 2009; Azzella et al., 2013b; Bolpagni, 2013a).

Generally, Chara-dominated vegetation has a low species richness and is strictly controlled by water nutrient content (especially by phosphorous availability) (Blindow,

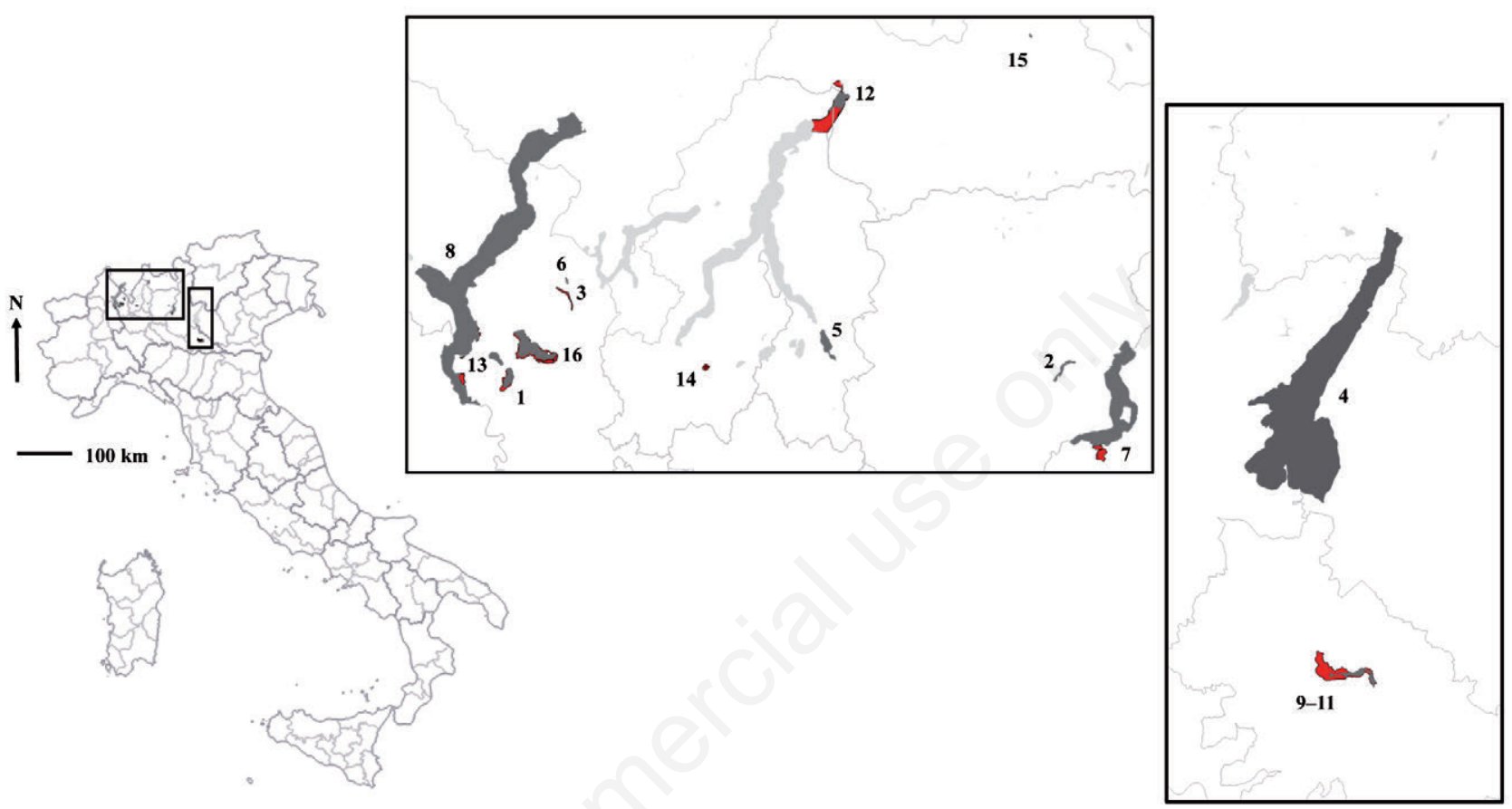

Fig. 1. Study area; the spatial distribution of the lakes analyzed (in dark grey), and the Natura 2000 sites (in red) are reported; see Tab. 1 and Tab. 2 for the Natura 2000 site codes and the lake names, respectively.

Tab. 2. Lakes features and sampling effort for each investigated lake.

\begin{tabular}{|c|c|c|c|c|c|c|c|c|c|c|}
\hline & Lake & $\begin{array}{c}\text { Alt } \\
\text { (m asl) }\end{array}$ & $\begin{array}{c}A \\
\left(\mathrm{~km}^{2}\right)\end{array}$ & $\begin{array}{c}\text { D } \\
(\mathrm{m})\end{array}$ & $\begin{array}{c}\mathrm{V} \\
\left(\mathrm{m}^{3} 10^{6}\right)\end{array}$ & $\begin{array}{l}\text { SD } \\
(\mathrm{m})\end{array}$ & $\begin{array}{c}\mathrm{TP} \\
\left(\mu \mathrm{g} \mathrm{L}^{-1}\right)\end{array}$ & IY & \#TR & \#SP \\
\hline 1 & Comabbio & 243 & 3.6 & 8 & 16.6 & 3.23 & 5.3 & 2008 & 23 & 78 \\
\hline 2 & Endine & 334 & 2.1 & 9 & 11.9 & 2.42 & 19.0 & 2008 & 67 & 157 \\
\hline 3 & Ganna & 390 & 0.1 & 3 & 0.1 & 2.50 & 2.5 & 2008 & 5 & 15 \\
\hline 4 & Garda & 65 & 368.0 & 350 & 49031.0 & 8.20 & 17.7 & 2011 & 82 & 760 \\
\hline 5 & Garlate & 205 & 4.6 & 34 & 70.0 & 5.62 & 23.0 & 2011 & 20 & 164 \\
\hline 6 & Ghirla & 415 & 3.2 & 14 & nd & 4.93 & 2.5 & 2008 & 18 & 74 \\
\hline 7 & Iseo & 185 & 61.0 & 251 & 7600.0 & 4.67 & 61.5 & 2008 & 109 & 743 \\
\hline 8 & Maggiore & 193 & 213.0 & 370 & 37500.0 & 6.42 & 4.4 & 2012 & 198 & 1056 \\
\hline 9 & Mantova Middle & 15 & 3.7 & 12 & nd & 0.85 & 50.0 & 2010 & 28 & 65 \\
\hline 10 & Mantova Inferior & 15 & 1.5 & 9 & nd & 0.82 & 37.5 & 2010 & 20 & 51 \\
\hline 11 & Mantova Superior & 18 & 1.1 & 15 & nd & 0.99 & 55.0 & 2010 & 45 & 119 \\
\hline 12 & Mezzola & 200 & 5.9 & 69 & 149.0 & 2.72 & 11.3 & 2011 & 30 & 189 \\
\hline 13 & Monate & 266 & 2.5 & 34 & 45.0 & 8.42 & 2.5 & 2008 & 40 & 172 \\
\hline 14 & Montorfano & 397 & 0.5 & 7 & 1.9 & 2.83 & 20.5 & 2012 & 12 & 48 \\
\hline 15 & Palù & 1921 & 0.2 & 50 & nd & 6.43 & 5.0 & 2011 & 10 & 52 \\
\hline 16 & Varese & 238 & 14.8 & 26 & 160.0 & 3.38 & 39.3 & 2008 & 44 & 130 \\
\hline
\end{tabular}

Alt, altitude; $A$, area; D, depth; V, volume; SD, Secchi disk; TP, total phosphorous; IY, investigation year; \#TR, total number of transects; \#SP, sampling plots; nd, not detected. 
1992). Since the Chara-dominated communities in lakes in northern Italy have seldom been investigated, few data are available on their composition and conservation status (Bolpagni et al., 2013). By contrast, more detailed investigations have been conducted on the volcanic lakes of central Italy (Azzella et al., 2013a, b, 2014; Bolpagni et al., 2016). The free-floating and rhizophytic plant communities are found both in eutrophic lakes and ponds. Almost all aquatic plant communities can be referred to this habitat type (e.g., Lemnetea and Potametea vegetation classes) (Biondi et al., 2009), including free-floating [e.g., Lemna ssp. or Salvinia natans (L.) All. dominated stands] and rooted vegetation consisting of both submerged (e.g., Vallisneria natans L., Potamogeton lucens L. dominated stands) and emergent [e.g., Nuphar lutea (L.) Sm., Nymphaea alba L., Potamogeton natans L. dominated stands] plant communities (Bolpagni and Piotti, 2015, 2016).

No record of the presence of EU habitat 3140 is present in the standard data forms of the Natura 2000 sites, whereas the presence of EU habitat 3150 is recorded in 8 out of 10 lakes (lakes Comabbio, Iseo, Maggiore, Mantova Superior, Middle and Inferior, Mezzola, and Varese)
(Tab. 1). Furthermore, no standardized information on any EU habitats is available for the lakes outside the Natura 2000 sites (lakes Endine, Garda, Garlate, Ghirla, Monate, and Palù). Thus, the data currently available indicate that EU habitat 3140 is not present, whereas EU habitat 3150 covers $\sim 298$ ha.

\section{Study design and data analysis}

We analyzed data collected in WFD monitoring surveys conducted between 2009 and 2012. Data included SD and TP values (Tab. 2) and the depth of macrophyte distribution. Macrophyte data was collected by applying the Italian national protocol, as described by Oggioni et al. (2011). Accordingly, the lakeshores were divided into homogeneous sections by inspecting helophytic and macrophyte vegetation. Data on macrophytes were recorded from a depth of $0.5 \mathrm{~m}$ to the maximum depth of colonization at 1-meter depth intervals along transects in a randomly selected section (Bolpagni, 2013a,b). The cover-abundance - expressed as a percentage - was estimated for all the taxa identified.

Three different morpho-functional groups of taxa were identified (Tab. 3) on the basis of the diagnostic

Tab. 3. Total representativeness of diagnostic taxa (total sampling plots colonized) of the EU habitat codes 3150 (natural eutrophic lakes; 1: free-floating and floating-leaved rhizophyte-dominated stands, and 2: submerged plant-dominated stands) and 3140 (3: charophyte-dominated benthic communities).

\begin{tabular}{|c|c|c|c|}
\hline Habitat code & & Species & Total \\
\hline 3150 & 1 & Nuphar lutea (L.) Sm. & 97 \\
\hline 3150 & 1 & Nymphaea alba L. & 312 \\
\hline 3150 & 1 & Nymphoides peltata (S.G. Gmel.) Kuntze & 40 \\
\hline 3150 & 1 & Trapa natans L. & 241 \\
\hline 3150 & 2 & Ceratophyllum demersum $\mathrm{L}$. & 1651 \\
\hline 3150 & 2 & Myriophyllum spicatum L. & 1683 \\
\hline 3150 & 2 & Najas marina $\mathrm{L}$. & 1849 \\
\hline 3150 & 2 & Najas minor All. & 73 \\
\hline 3150 & 2 & Potamogeton lucens L. & 31 \\
\hline 3150 & 2 & Potamogeton pectinatus L. & 297 \\
\hline 3150 & 2 & Potamogeton perfoliatus L. & 916 \\
\hline 3150 & 2 & Potamogeton pusillus L. & 274 \\
\hline 3150 & 2 & Potamogeton trichoides Cham. \& Schltdl. & 20 \\
\hline 3150 & 2 & Vallisneria spiralis $\mathrm{L}$. & 2809 \\
\hline 3150 & 2 & Zanichellia palustris L. & 582 \\
\hline 3140 & 3 & Chara globularis Thuiller & 1439 \\
\hline 3140 & 3 & Chara intermedia A.Braun & 36 \\
\hline 3140 & 3 & Chara tomentosa Linnaeus & 25 \\
\hline 3140 & 3 & Nitella flexilis (Linnaeus) C.Agardh & 61 \\
\hline 3140 & 3 & Nitella gracilis (J.E.Smith) C.Agardh & 27 \\
\hline 3140 & 3 & Nitella hyalina (De Candolle) C.Agardh & 36 \\
\hline 3140 & 3 & Nitellopsis obtusa (N.A.Desvaux) J.Groves & 84 \\
\hline
\end{tabular}


power of each species detected in terms of life-growth form and the phytosociological literature. The free-floating and floating-leaved rhizophytes (group 1) and submerged rhizophytes (2) were referred to EU habitat 3150; charophytes (3) were instead referred to EU habitat 3140. Taxa with at least 20 records $(=22)$ were considered in the analysis (Supplementary Tab. 1). Overall, 751 transects were analyzed, which resulted in a total of 3,873 plots being investigated and 14,130 taxon records being collected. We considered a habitat present when at least one stonewort or vascular diagnostic species was present with an estimated cover-abundance higher than 35\%.

Simple regression analysis was used to evaluate the relationships between the depth distribution of the EU habitats being analyzed and SD as a proxy of the underwater light conditions. The area and depth descriptors were excluded from the analyses owing to their high collinearity with SD. All the analyses were performed in the R environment (R Development Core Team, 2016), considering the depth distribution of the EU habitats' diagnostic taxa, considering the three morpho-functional groups of species separately: i) free-floating and floating-leaved plants, ii) submerged plants, and iii) charophytes.

\section{RESULTS}

\section{Macrophyte EU habitat distribution patterns}

Based on the diagnostic species spatial arrangement, we confirmed the presence of EU habitat 3150 in all the lakes investigated; by contrast, EU habitat 3140 was present in only 7 of the 16 lakes (43.8\%) (Fig. 2).

The emergent plant communities of EU habitat 3150 grew to a maximum depth of $4.5 \mathrm{~m}$ (recorded at Lake Monate), with a mean colonization depth of $1.3 \pm 0.8 \mathrm{~m}$ ( \pm SD) (Fig. 2), whilst the submerged EU 3150 plant communities grew down to $10.5 \mathrm{~m}$ (recorded at Lake Garda), with a mean colonization depth of $2.9 \pm 1.9 \mathrm{~m}$ (Fig. 2). The emergent EU 3150 communities were dominated by N. lutea, N. alba, Nymphoides peltata (S.G. Gmel.) Kuntze, and Trapa natans L., the submerged communities by Ceratophyllum demersum L., Myriophyllum spicatum L., Najas marina L., Potamogeton lucens L., P. pectinatus L., P. perfoliatus L., and Vallisneria spiralis L.

EU habitat 3140 exhibited a greater variability in terms of colonized depths than the vascular plant communities, with a maximum depth of $16.5 \mathrm{~m}$ at Lake Garda, and a mean colonization depth of $3.8 \pm 2.6 \mathrm{~m}$ (Fig. 2). The prevalent (dominant) species were Chara globularis Thuiller, C. intermedia A.Braun, C. tomentosa Linnaeus, Nitella flexilis (Linnaeus) C.Agardh, and Nitellopsis obtusa (N.A.Desvaux) J.Groves.

\section{Depth distribution of lacustrine EU habitats vs SD}

The linear regression analysis revealed that the mean depth range colonized by submerged vegetation correlated with SD (Fig. 3). Both submerged EU 3150 and Charadominated communities positively correlated with $\mathrm{SD}\left(\mathrm{R}^{2}\right.$ adj=0.501, $\mathrm{P}<0.01, \mathrm{n}=16$, and $\mathrm{R}^{2}$ adj $=0.737, \mathrm{P}<0.01$, $\mathrm{n}=7$, respectively); by contrast, no correlation was detected between emergent plant communities (EU 3150) and $\mathrm{SD}\left(\mathrm{R}^{2}\right.$ adj $\left.=0.138, \mathrm{P}=0.864, \mathrm{n}=9\right)$.

\section{DISCUSSION}

The present data confirm that information collected during WFD monitoring programs are able to make an important contribution to our knowledge of aquatic EU habitats in lacustrine environments. These results may, in addition, be used to evaluate the effectiveness of local water conservation policies. For example, the fact that EU habitat 3140 had not previously been found in the Natura 2000 sites considered in this study may be due to a progressive improvement in the chemical and physical conditions of lakes. As is widely known, Chara-dominated communities are considered to be among the aquatic habitats that are most sensitive to external pressures, especially in terms of nutrient loading (e.g., phosphorous availability or algal blooms) (Blindow, 1992; Auderset Joye et al., 2002). We cannot, however, exclude inaccuracies in the assessment of the structure and composition of the submerged habitats during the past routine HD surveys given the intrinsic difficulties encountered when monitoring water bodies (Azzella et al., 2013b), as well as the rarity or temporal dynamicity of these communities (Bolpagni et al., 2016). Nevertheless, these uncertainties further support the pivotal contribution of the use of the standardized approaches adopted within the framework of the WFD to integrate current knowledge on the presence, areal distribution and representativeness of aquatic EU habitats.

\section{Aquatic EU habitats in the lakes of Lombardy}

On the basis of Lombardy Regional Environmental Protection Agency surveys, the results of our study highlight the local predominance of vascular submerged communities in the depth range of 1 to $4 \mathrm{~m}$, which are dominated by $V$. spiralis, N. marina and M. spicatum. Indeed, vascular plant communities were limited to the upper water depths, whereas communities that live at the maximum growing depths in lakes are composed of non-vascular species (Hutchinson, 1975). Accordingly, we substantiated the existence of a fairly clear differentiation between the two habitats we analyzed (EU 3140 and 3150 ), thereby highlighting the pivotal role played by the ability of vascular and charophyte species to capture light in shaping the depth distribution of aquatic vegetation. In- 
deed, EU habitat 3140 was found to mainly occur in deep lakes, not all of which are included in the local Natura 2000 network. This suggests that the regional policy regarding this habitat needs to be reassessed. This finding is in agreement with a preliminary evaluation of the repre- sentativeness of Chara-dominated stands in Lake Garda, which may account for approximately $20 \%$ of the overall area occupied by this habitat at national scale (1000-1200 ha out of a total of $\sim 5000 \mathrm{ha}$ ) (Bolpagni et al., 2013).

In the lakes we investigated, EU habitats 3140 and

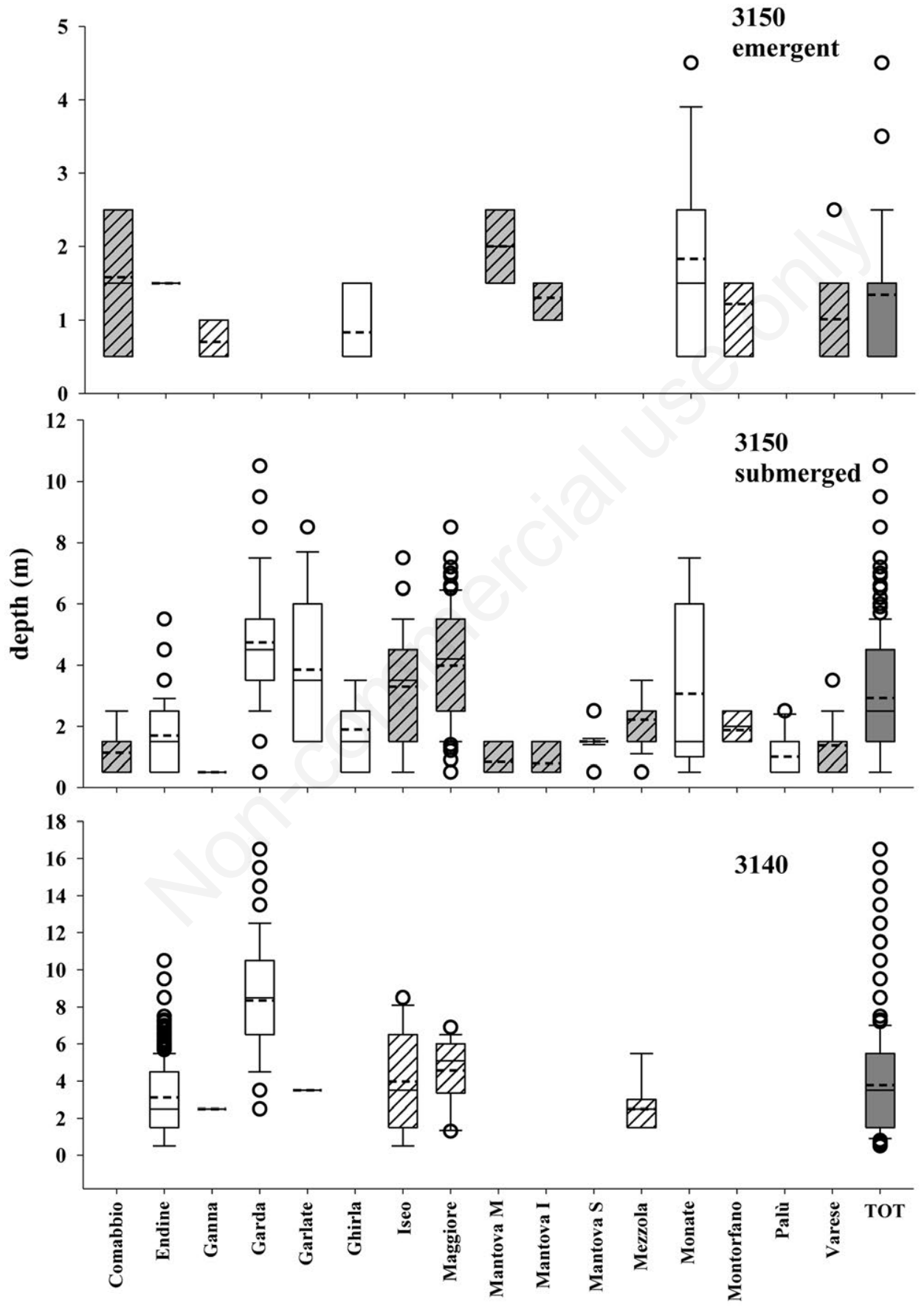

Fig. 2. Box plot graph of the depth distribution of the diagnostic species of the EU habitats 3150 (considering both the emergent and submerged plant communities) and 3140 . The box indicates $25^{\text {th }}-75^{\text {th }}$ percentile; the solid and dotted lines indicate median and mean values, respectively. The lakes with previous habitat records are highlighted in grey, the coarse pattern indicates the lakes included in the Natura 2000 network. Mantova M, Mantova Middle; Mantova I, Mantova Inferior; Mantova S, Mantova Superior; TOT, all data together. 
3150 displayed a comparable range of colonized depths that was partially overlapped (0.5-4.5 $\mathrm{m}$ vs $1.5-5.6 \mathrm{~m}$; Fig. 3), which reflects the wide range of SD conditions considered. Hence, the variability in underwater light conditions affects both the presence/absence and the extent of the depth range colonized by diagnostic species, which change significantly in different lakes. Although the dataset we used was limited in size, our findings corroborate the strong interdependence between aquatic habitat depth ranges and the underwater light environment (Canfield et al., 1985; Chambers and Kalff, 1985). This is substantiated by the differences that emerged between the linear regression models generated, with the increased steepness of the estimated slope revealing a greater sensitivity of charophytes to a progressive worsening in water conditions (Fig. 3). Even a small reduction in SD may be assumed to be associated with a non-negligible reduction in the area occupied by Chara-dominated stands. By contrast, vascular-dominated stands appear to be more "resilient", with a lesser dependency on SD variations. One explanation for the findings yielded by the lakes we investigated may be the replacement of sensitive aquatic vascular plants (mainly species belonging to the genus Potamogeton) by more tolerant species (e.g., M. spicatum, $V$. spiralis) or alien taxa, such as Lagarosiphon major (Ridl.) Moss and Elodea nuttallii (Planch.) H. St. John (Bolpagni et al., 2015; Soana and Bartoli, 2013, 2014).

\section{Practical remarks on the WFD and HD integration}

Although the standardized WFD methods used for macrophyte characterization cannot be considered exhaustive to describe vegetation, mainly because they do not provide a full and detailed floristic account of plant communities (Oggioni et al., 2011), it is worth bearing in mind that their primary objective is the ecological classification of water bodies. This type of information can be used to define the spatial distribution and depth rearrangement of the diagnostic species of many EU habitats of conservation concern. Furthermore, if compared with the methods commonly used to characterize aquatic vegetation (i.e., phytosociology), the standardized WFD methods ensure the acquisition of ancillary data on the physical and chemical conditions of the colonized environments. These data are important as a means of assessing the quality of habitats and colonized sites as well as of evaluating the future prospects of habitats (Collins et al., 2012; Louette et al., 2015 and references therein). This is a focal point that supports the integration of current programs aimed at protecting lacustrine aquatic EU habitats not only in Lombardy, but also across Europe as a whole. Bearing all this in mind, we wish to stress the need to implement strategies for the conservation of aquatic habitats by integrating trophic trends of lakes in terms of nutrient availability and water transparency as well as of the rela- tive size of water bodies (Azzella et al., 2014b).

By focusing on the distribution patterns of aquatic habitats of conservation concern, this paper attempts, to our knowledge for the first time, to actively combine the WFD directive with the HD. The standard WFD data on macrophytes appear to complement the needs and the requirements of HD, especially for defining the area (range) occupied by a specific lacustrine aquatic EU habitat. The use of data collected by the WFD will also enable us to make robust comparisons between biogeographic regions and states, thereby strengthening evaluations of current trends
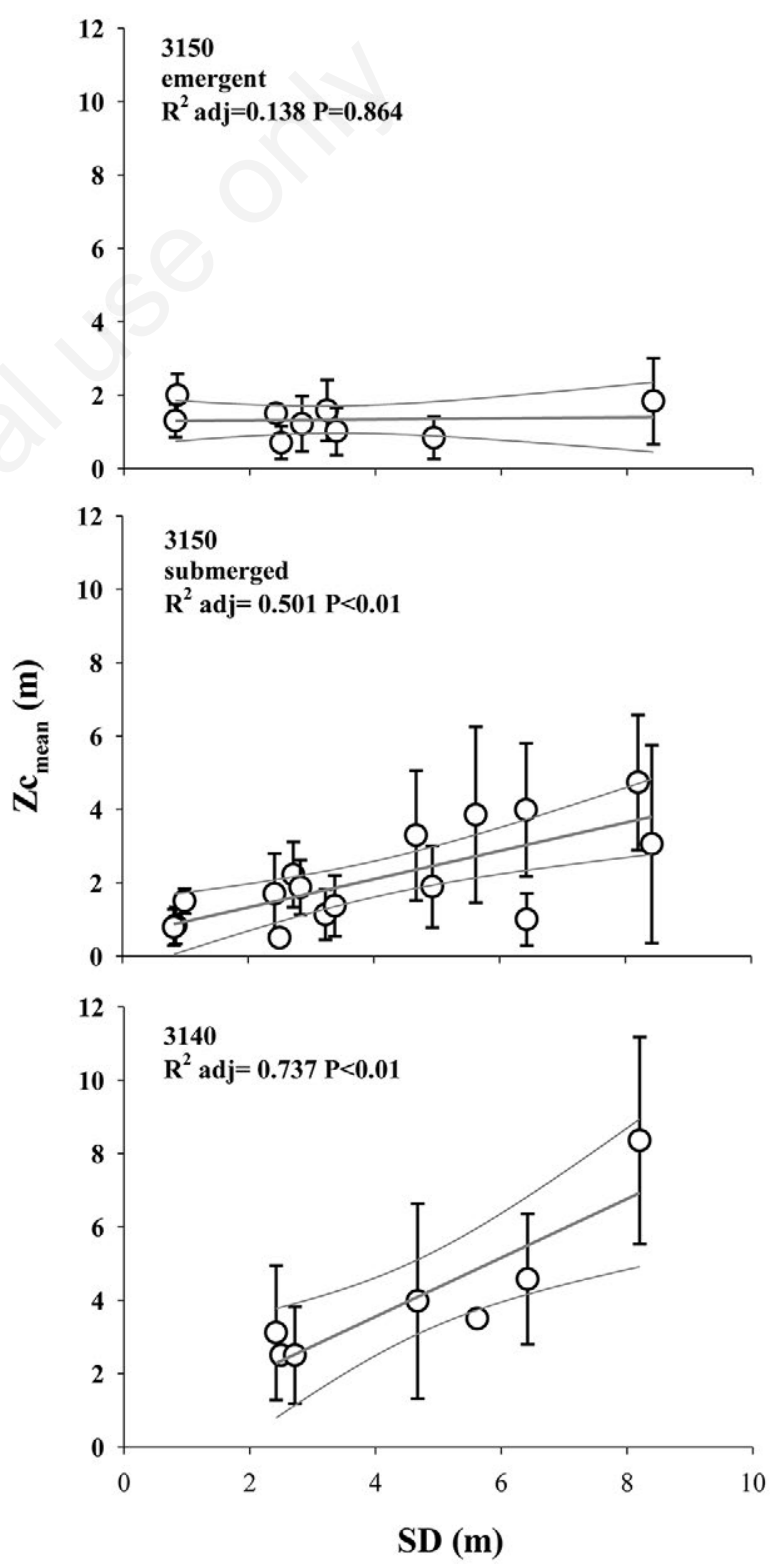

Fig. 3. Linear regression between water transparency, expressed as Secchi disk (SD, in $\mathrm{m}$ ), and the mean depth of the habitat distribution $\left(\mathrm{Zc}_{\text {mean }} \pm\right.$ standard deviation, in $\left.\mathrm{m}\right)$. 
in aquatic vegetation on a large spatial scale. Furthermore, the possibility of gathering reliable and valid information on the physical and chemical conditions of water and sediments may make a fundamental contribution to defining favourable conservation conditions of habitats as well as to planning the distribution of areas of aquatic vegetation in response to climate change or direct human impacts (i.e., pollution, water abstraction). This is especially important for aquatic environments, which are among the most vulnerable ecosystems in the world (Verhoeven et al., 2006).

Within this context, a better integration between HD, WFD and remote sensing techniques may represent a key strategy to obtain reliable information on the ranges occupied and to examine current dynamic trends in aquatic vegetation, as has previously been shown by many authors (Villa et al., 2013, 2014, 2015; Giardino et al., 2015). Indeed, remote sensing is an effective tool for recognizing and mapping vegetation thanks to the advantages of the synoptic view (in time and space) over the field survey (Vis et al., 2003; Silva et al., 2008). Furthermore, the vegetation indices yielded by airborne and satellite images can effectively be used to implement standard monitoring approaches, thereby providing new opportunities in the assessment of vegetation status, growth or biophysical features. This may be considered a further step toward maximizing monitoring efforts and assessment outcomes.

\section{CONCLUSIONS}

This study highlights, for the first time, the usefulness of approaches implemented and adopted by the WFD to assess macrophyte communities in lakes as a means of also evaluating the presence of EU habitats and the size of the areas they occupy. Furthermore, the data collected within the framework of the WFD monitoring networks are comparable because they are obtained by means of similar sampling procedures, calibrated at the ecoregion scale by specific Geographical Intercalibration Groups. In addition, the use of these data may minimize the limitations usually associated with local flora and vegetation surveys, which are often restricted to a single, or a few, Natura 2000 sites. WFD data effectively address the urgent need to extend the information available on the presence and state of conservation of EU habitats beyond the Natura 2000 network.

\section{ACKNOWLEDGMENTS}

The authors are very grateful for the fruitful discussions with Dr. F. Moroni and Dr. C. Farioli of the Po River Basin Authority (AdBPo). A special thanks to Dr. F. Buzzi (Lombardy Regional Environmental Protection Agency) for his contribution to this project, and to Dr. A. Laini for his support in the data analysis.

\section{REFERENCES}

Auderset Joye D, Castella E, Lachavanne JB, 2002. Occurrence of Characeae in Switzerland over the last two centuries (1800-2000). Aquat. Bot. 72:369-385.

Azzella MM, Bolpagni R, Oggioni A, 2014a. A preliminary evaluation of lake morphometric traits influence on the maximum colonization depth of aquatic plants. J. Limnol. 73:400-406.

Azzella MM, Iberite M, Fascetti S, Rosati L, 2013a. Loss detection of aquatic habitats in Italian volcanic lakes using historical data. Plant Biosyst. 147:521-524.

Azzella MM, Ricotta C, Blasi C, 2013b. Aquatic macrophyte diversity assessment: Validation of a new sampling method for circular-shaped lakes. Limnologica 43:492-499.

Azzella MM, Rosati L, Iberite M, Bolpagni R, Blasi C, 2014b. Changes in aquatic plants in the Italian volcanic-lake system detected using current data and historical records. Aquat. Bot. 112:41-47.

Beunen R, vand der Knaap WGM, Biesbroek GR, 2009. Implementation and integration of EU environmental directives. Exp. Netherlands Environm. Poll. Governan. 19:57-69.

Biondi E, Blasi C, Burrascano S, Casavecchia S, Copiz R, Del Vico E, Galdenzi D, Gigante D, Lasen C, Spampinato G, Venzanzoni R, Zivkovic L, 2009. [Manuale italiano di interpretazione degli habitat della Direttiva 92/43/CEE].[Book in Italian]. Accessed on: 10 December, 2016. Available from: http://www.vnr.unipg.it/habitat

Blindow H, 1992. Decline of charophytes during eutrophication: comparison with angiosperms. Freshwater Biol. 28:9-14.

Bolpagni R, 2013a. Macrophyte richness and aquatic vegetation complexity of the Lake Idro (Northern Italy). Ann. Bot. (Roma) 3:77-85.

Bolpagni R, 2013b. Multimetric indices based on vegetation data for assessing ecological and hydromorphological quality of a man-regulated lake. Ann. Bot. (Roma) 3:87-95.

Bolpagni R, Piotti A, 2015. Hydro-hygrophilous vegetation diversity and distribution patterns in riverine wetlands in an agricultural landscape: a case study from the Oglio River (Po plain, Northern Italy). Phytocoenologia 45:69-84.

Bolpagni R, Piotti A, 2016. The importance of being natural in a human-altered riverscape: Role of wetland type in supporting habitat heterogeneity and vegetation functional diversity. Aquat. Conserv. 26:1168-1183.

Bolpagni R, Bettoni E, Bonomi F, Bresciani M, Caraffini K, Costaraoss S, Giacomazzi F, Monauni C, Montanari P, Mosconi MC, Oggioni A, Pellegrini G, Zampieri C, 2013. Charophytes of the Lake Garda (Northern Italy): a preliminary assessment of diversity and distribution. J. Limnol. 72:388-393.

Bolpagni R, Laini A, Soana E, Tomaselli M, Nascimbene J, 2015. Growth performance of Vallisneria spiralis under oligotrophic conditions supports its potential invasiveness in mid-elevation freshwaters. Weed Res. 55:185-194.

Bolpagni R, Laini A, Azzella MM, 2016. Short-term dynamics of submerged aquatic vegetation diversity and abundance in deep lakes. Appl. Veg. Sci. 19:711-723.

Canfield D, Langeland K, Linda S, Haller W, 1985. Relations between water transparency and maximum depth of macrophyte colonization in lakes. J. Aquat. Plant. Manage. 23:25-28. 
Chambers PA, Kalff J, 1985. Depth distribution and biomass of submersed aquatic macrophyte communities in relation to Secchi depth. Can. J. Fish. Aquat. Sci. 42:701-709.

Collins A, Dieudonne-Guy O, Hoare D, Voulvoulis N, 2012. Implementing the Water Framework Directive: a transition from established monitoring networks in England and Wales. Environ. Sci. Pol. 17:49-61.

Ecke F, Hellsten S, Mjelde M, Kuoppala M, Schlacke S, 2010. Potential conflicts between environmental legislation and conservation exemplified by aquatic macrophytes. Hydrobiologia 656:107-115.

Evans D, Arvela M, 2011. Assessment and reporting under Article 17 of the Habitats Directive - Explanatory Notes \& Guidelines for the period 2007-2012. ETC-BD.

Dale H, 1986. Temperature and light: the determining factors in maximum depth distribution of aquatic macrophytes in Ontario, Canada. Hydrobiologia 133:73-77.

Duarte CM, Kalff J, 1990. Patterns in the submerged macrophyte biomass of lakes and the importance of the scale of analysis in the interpretation. Can. J. Fish. Aquat. Sci. 47:357-363.

European Union, 1992. Council Directive 92/43/ECC of 21 May 1992 on the conservation of natural habitats and wild fauna and flora. OJ L 206, 22/07/1992, pp. 7-50.

European Union, 2000. Directive 2000/60/EC of the European Parliament and of the Council of 23 October 2000 establishing a framework for Community action in the field of water policy. OJ L 327, 22/12/2000, pp. 1-73.

Genkai-Kato M, Carpenter SR, 2005. Eutrophication due to phosphorus recycling in relation to lake morphometry, temperature, and macrophytes. Ecology 86:210-219.

Giardino C, Bresciani M, Valentini E, Gasperini L, Bolpagni R, Brando VE, 2015. Airborne hyperspectral data to assess suspended particulate matter and aquatic vegetation in a shallow and turbid lake. Remote Sens. Environ. 157:48-57.

Janauer GA, Albrecht J, Stratmann L, 2015. Synergies and Conflicts between Water Framework Directive and Natura 2000: Legal Requirements, Technical Guidance and Experiences from Practice, p. 9-29. In: S. Ignar, M. Grygoruk (eds.), Wetlands and Water Framework Directive. GeoPlanet: Earth and Planetary Sciences.

Hutchinson G, 1975. A treatise on limnology: limnological botany. 3. Wiley \& Sons, New York: 660 pp.

Louette G, Adriaens D, Paelinckx D, Hoffmann M, 2015. Implementing the Habitats Directive: How science can support decision making. J. Nature Conserv. 23:27-34.
Oggioni A, Buzzi F, Bolpagni R, 2011. [Indici macrofitici per la valutazione della qualità ecologica dei laghi: MacroIMMI e MTIspecies, p. 52-80]. In: A. Marchetto, A. Lugliè, B.M. Padedda, M.A. Mariani, N. Sechi, N. Salmaso, G. Morabito, F. Buzzi, M. Simona, L. Garibaldi, A. Oggioni, R. Bolpagni, B. Rossaro, A. Boggero, V. Lencioni, L. Marziali, P. Volta, M. Ciampittiello (eds.), [Indici per la valutazione della qualità ecologica dei laghi], Report CNR-ISE 03-11. [Book in Italian]. CNR Publication.

R Development Core Team, 2016. R: A language and environment for statistical computing. R Foundation for Statistical Computing, Vienna, Austria. Available from: http://www. R-project.org

Silva TSF, Costa MPF, Melack JM, Novo EMLM, 2008. Remote sensing of aquatic vegetation: Theory and applications. Environ. Monit. Assess. 140:131-145.

Soana E, Bartoli M, 2013. Seasonal variation of radial oxygen loss in Vallisneria spiralis L.: an adaptation to sediment redox? Aquat. Bot. 104:228-232.

Soana E, Bartoli M, 2014. Seasonal regulation of nitrification in a rooted macrophyte (Vallisneria spiralis L.) meadow under eutrophic conditions. Aquat. Ecol. 48:11-21.

Søndergaard M, Phillips G, Hellsten S, Kolada A, Ecke F, Mäemets H, Mjelde M, Azzella MM, Oggioni A, 2013. Maximum growing depth of submerged macrophytes in European lakes. Hydrobiologia 704:165-177.

Verhoeven JTA, Arheimer B, Yin C, Hefting MM, 2006. Regional and global concerns over wetlands and water quality. Trends Ecol. Evol. 21:96-103.

Villa P, Laini A, Bresciani M, Bolpagni R. 2013. A remote sensing approach to monitor the conservation status of lacustrine Phragmites australis beds. Wetl. Ecol. Manage. 21:399-416.

Villa P, Bresciani M, Braga F, Bolpagni R, 2014. Comparative assessment of Broadband Vegetation Indices over aquatic vegetation. IEEE J. Sel. Top. Appl. 7:3117-3127.

Villa P, Bresciani M, Bolpagni R, Pinardi M, Giardino C, 2015. A rule-based approach for mapping macrophyte communities using multi-temporal aquatic vegetation indices. Remote Sens. Environ. 171:218-233.

Vis C, Hudon C, Carignan R, 2003. An evaluation of approaches used to determine the distribution and biomass of emergent and submerged aquatic macrophytes over large spatial scales. Aquat. Bot. 77:187-201. 